\title{
Effects of COVID-19 Infection during Pregnancy and Neonatal Prognosis: What Is the Evidence?
}

\author{
Álvaro Francisco Lopes de Sousa $1,2, * \mathbb{C}$, Herica Emilia Félix de Carvalho ${ }^{2} \mathbb{B}$,

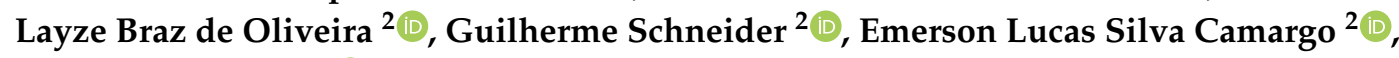 \\ Evandro Watanabe ${ }^{2}\left(\mathbb{D}\right.$, Denise de Andrade ${ }^{2}$, Ana Fátima Carvalho Fernandes ${ }^{3}$, \\ Isabel Amélia Costa Mendes ${ }^{2} \mathbb{D}$ and Inês Fronteira ${ }^{1}$ (D) \\ 1 Global Health and Tropical Medicine, Instituto de Higiene e Medicina Tropical, Universidade Nova de \\ Lisboa, 1349-008 Lisboa, Portugal; ifronteira@ihmt.unl.pt \\ 2 Human Exposome and Infectious Diseases Network (HEID), Escola de Enfermagem de Ribeirão Preto, \\ Universidade de São Paulo, 14040-902 Ribeirão Preto, Brazil; hericacarvalho@usp.br (H.E.F.d.C.); \\ layzebraz@usp.br (L.B.d.O.); guilherme.schneider@usp.br (G.S.); lucmrg0@gmail.com (E.L.S.C.); \\ ewatanabe@forp.usp.br (E.W.); dandrade@eerp.usp.br (D.d.A.); iamendes@usp.br (I.A.C.M.) \\ 3 Nursing Department, Universidade Federal do Ceará, 60430-160 Fortaleza, Brazil; afcana@ufc.br \\ * Correspondence: alvarosousa@usp.br or sousa.alvaromd@gmail.com
}

Received: 24 April 2020; Accepted: 8 June 2020; Published: 11 June 2020

\begin{abstract}
Background: This study's aims are to assess the current evidence presented in the literature regarding the potential risks of COVID-19 infection among pregnant women and consequent fetal transmission. Methods: a systematic literature review assessing papers published in the most comprehensive databases in the field of health intended to answer the question, "What are the effects of COVID-19 infection during pregnancy, and what is the neonatal prognosis?" Results: 49 papers published in 2020 were eligible, presenting low levels of evidence. A total of 755 pregnant women and 598 infants were assessed; more than half of pregnant women had C-sections (379/65\%). Only $493(82 \%)$ infants were tested for SARS-CoV-2, nine ( $2 \%)$ of whom tested positive. There is, however, no evidence of vertical transmission based on what has been assessed so far, considering there are knowledge gaps concerning the care provided during and after delivery, as well as a lack of suitable biological samples for testing SARS-CoV-2. Conclusions: We cannot rule out potential worsening of the clinical conditions of pregnant women infected with SARS-CoV-2, whether the infection is associated with comorbidities or not, due to the occurrence of respiratory disorders, cardiac rhythm disturbances, and acid-base imbalance, among others. We recommend relentless monitoring of all pregnant women in addition to testing them before delivery or the first contact with newborns.
\end{abstract}

Keywords: COVID-19; SARS-CoV-2; pregnancy; fetal transmission; mother-to-child transmission

\section{Introduction}

On 30 January 2020, the World Health Organization (WHO) declared the outbreak of COVID-19, a respiratory disease caused by the new coronavirus SARS-CoV-2, as the sixth public health emergency of international concern [1,2] Due to its highly transmissible nature, by 9 April 2020, it had spread to five continents, and approximately 85,522 people had died [2].

Considering that transmission seems to mainly occur through contact with respiratory droplets [3] produced by an infected person, anticipating public health measures intended to control and prevent the infection, such as adherence to universal precautions, quarantine, and timely diagnosis, are options available to mitigate the transmission of COVID-19 [4].

Clinical manifestations range from asymptomatic cases and mild upper airway infection, up to severe and fatal cases with pneumonia and acute respiratory failure [5-7]. This variation is because 
people with prior diseases/comorbidities are less apt to fight the virus so that it is more likely to reach the lungs and cause pneumonia. Elderly individuals with comorbidities such as noncommunicable diseases and immunocompromised persons are at the highest risk of developing signs and symptoms of COVID-19 and having them worsened $[5,6]$.

It is, however, unknown how COVID-19 infection behaves in key populations more commonly susceptible to viral diseases, such as pregnant women [8], as well as whether there is the possibility of vertical transmission or premature birth.

The changes in the immune system of pregnant women make them more susceptible to infectious processes, in addition to the manifestations of the infection, with the risk of adverse maternal and neonatal complications, premature birth, spontaneous abortion, application of endotracheal intubation, restriction of intrauterine growth, hospitalization in an intensive care unit, renal failure, intravascular coagulopathy, and transmission to the fetus or newborn [9].

Current studies on the susceptibility of pregnant women to infection by COVID-19 are still incipient and adopt poor methods, and although transmission of the virus to the fetus or baby during delivery or pregnancy has not been proven, the presence of antibodies has already been identified, namely, specific IgG for viruses in neonatal serum samples [10].

Due to the need to provide evidence for clinical practice involving pregnant women, this study's objective is to assess current evidence presented in the literature regarding the potential risks of COVID-19 infection among pregnant women and consequent fetal transmission.

\section{Materials and Methods}

This systematic literature review [11], with no protocol registration, is intended to answer the question, "What are the effects of COVID-19 infection during pregnancy and what is the neonatal prognosis?" The PECO [12] method was adopted, in which

- $\quad$ Population $(\mathrm{P})=$ pregnant women;

- $\quad$ Exposure $(\mathrm{E})=$ COVID-19 infection;

- Comparison $(\mathrm{C})=$ has not been an object of study;

- Outcome $(\mathrm{O})=$ maternal and/or fetal infection by SARS-CoV-2.

A search was conducted in the following databases: US National Library of Medicine (PubMed), Scopus, Embase, ScienceDirect (Elsevier), Web of Science (WoS), Scholar Google, and preprints servers bioRxiv and medRxiv, as well as the bibliographic references of the selected papers (hand searching). These databases were selected due to their range and representativeness in the field of basic and health sciences. Terms that derived from the following expressions were used according to the databases/servers: "COVID-19" OR "SARS-CoV-2" AND "Pregnancy" AND "Perinatal". To avoid screening biases, two researchers with expertise in the method and topic under study independently and concomitantly searched all the databases on 25 and 26 May. The researchers had a discussion to reach a consensus about which papers would be included or excluded from the study, and a third reviewer mediated disagreements that prevented them from reaching a consensus.

Observational epidemiological studies and case reports addressing the clinical conditions of mother-fetus pairs and including primary data of patients over 18 years old were considered eligible. Manuscripts that contained only data from pregnant women, or only fetuses, or that did not address the period of delivery, such as puerperium, were disregarded. No restrictions regarding the period of publication or language were imposed. Review papers, opinions reports, local reports, abstracts of events, and similar works were excluded. Social, demographic, and clinical data included in the studies were collected.

The GRADE system was used to classify levels of evidence. The results are presented in terms of prevalence calculated in the study and combined results. 


\section{Results}

In total, 148 studies were initially identified, 20 of which were excluded because they were repeated. Of the 128 remaining studies, 56 were excluded for not addressing this review's objective. The full texts of 72 studies were analyzed, although 23 did not meet the eligibility criteria, so 49 studies remained and composed the final sample of this systematic review (Figure 1).

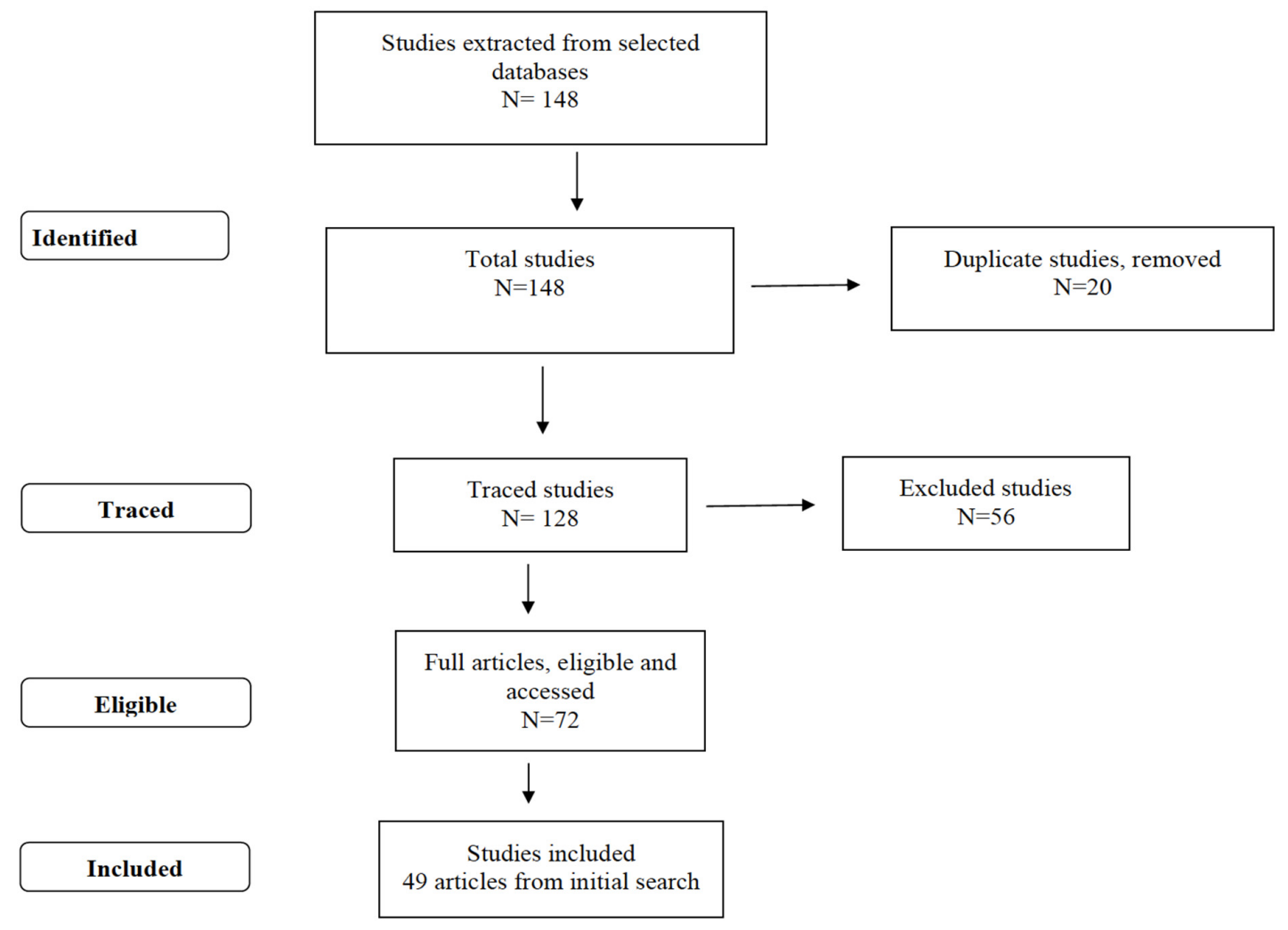

Figure 1. Study selection flowchart.

The studies were divided into 21 case reports (42\%) [13-33], 19 cross-sectional descriptive studies (40\%) [34-52], 7 cross-sectional analytical studies (14\%) [53-59], 1 case-control study (2\%) [60], and 1 cohort study (2\%) [61] (Table 1 ).

In Table 2, we present the characteristics of pregnant women and newborns, with social, demographic, and clinical data being collected. 
Table 1. Characteristics of included studies: reference, study design, location, level of evidence, and limitations.

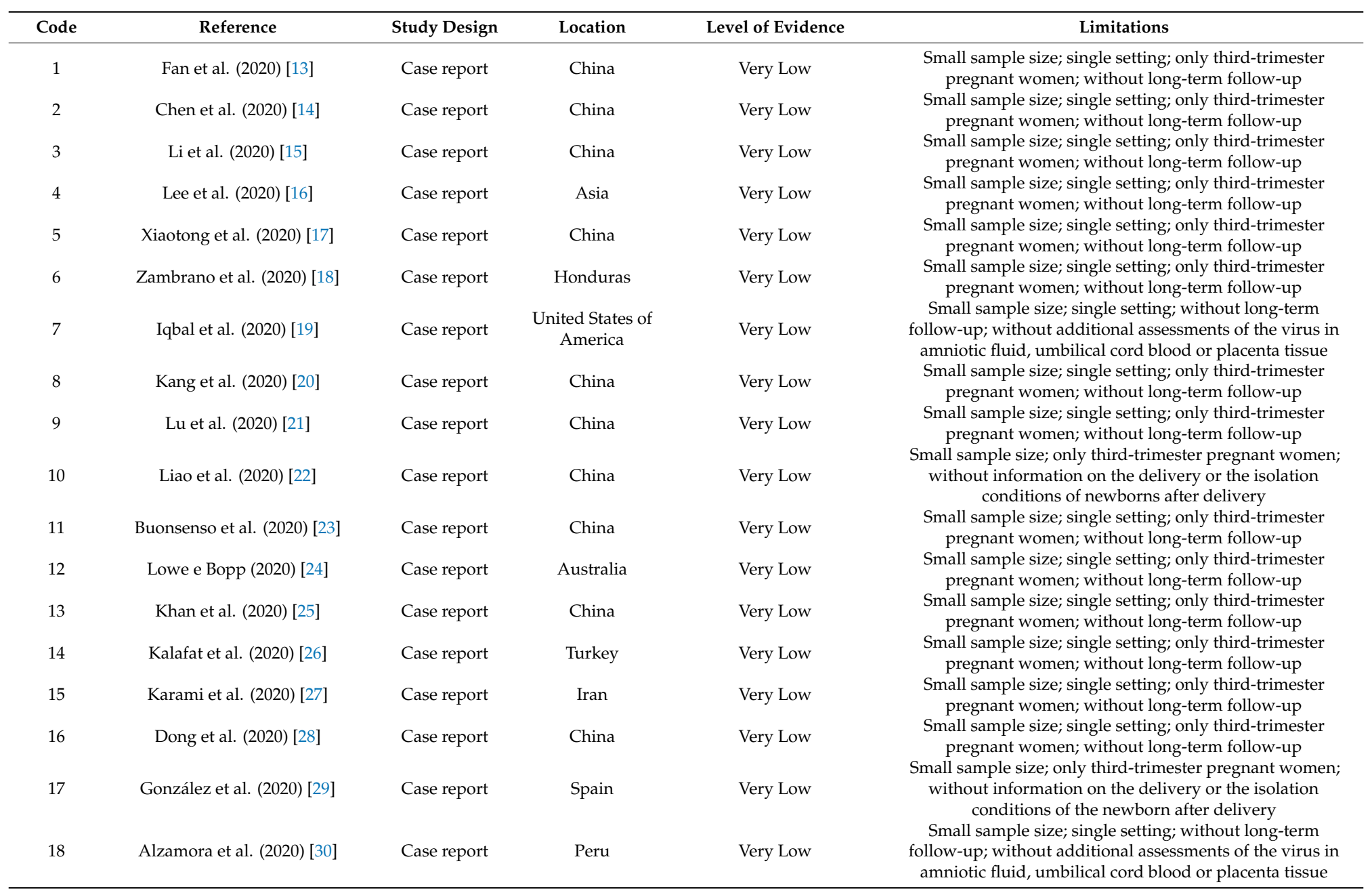


Table 1. Cont.

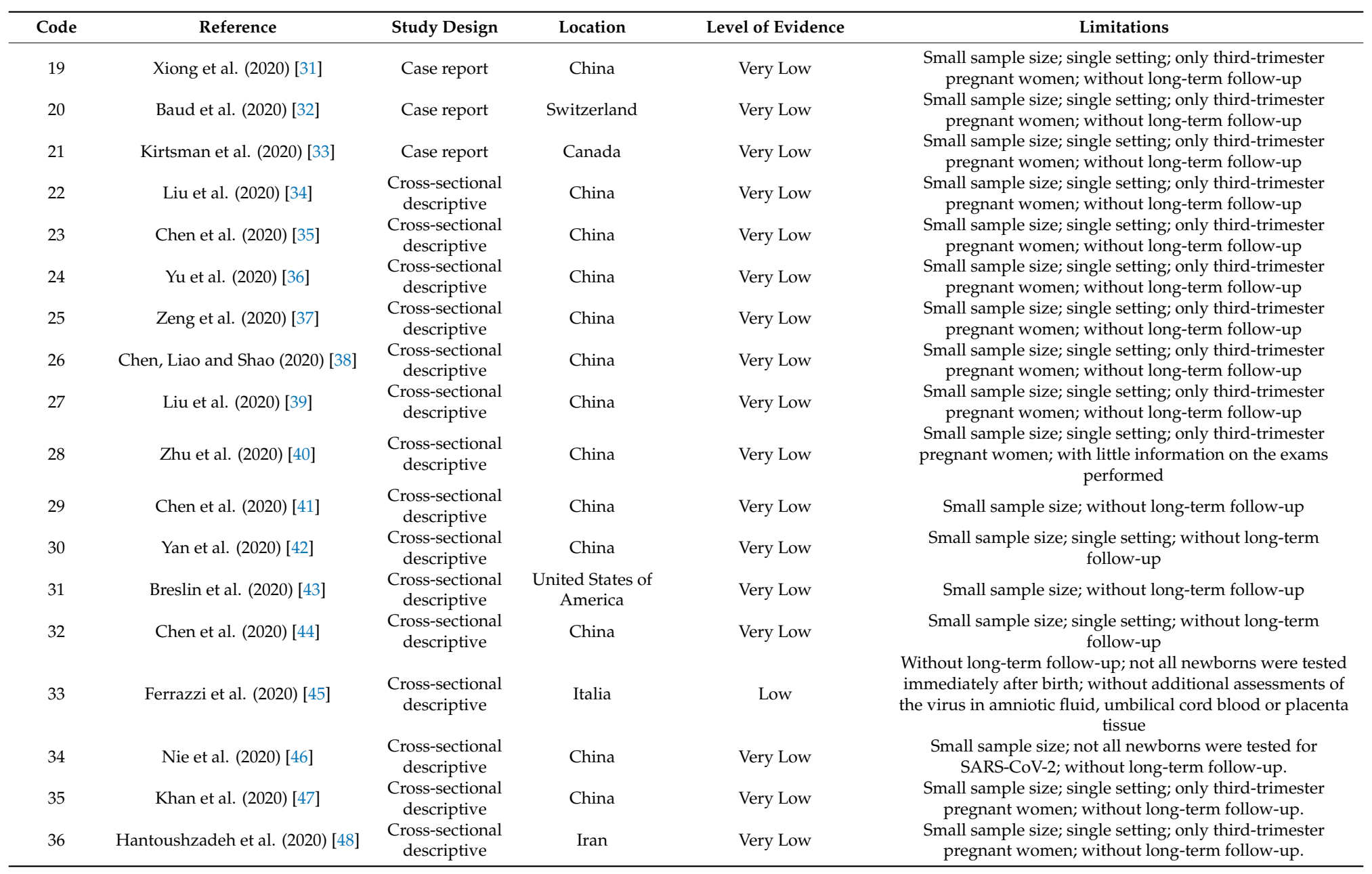


Table 1. Cont.

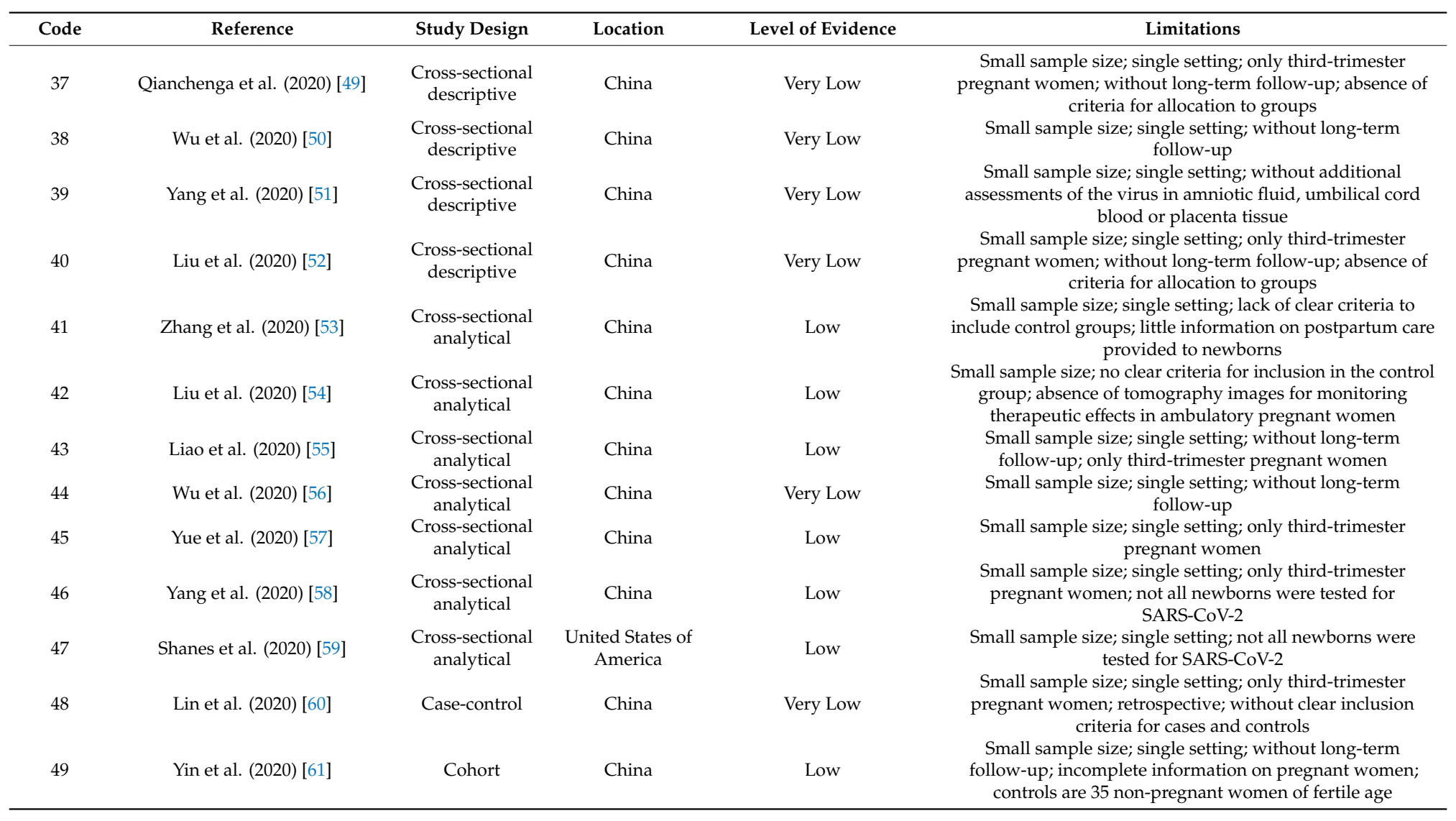


Table 2. Characteristics of included studies: study design, settings and participants, clinical, laboratory, and imaging findings of women, and type of delivery and clinical and laboratory findings of newborns.

\begin{tabular}{|c|c|c|c|c|}
\hline Code & Study Design & Setting and Participants & Clinical, Laboratory and Imaging Findings of Women and Type of Delivery & Newborns' Clinical and Laboratory Findings \\
\hline [13-33] & Case report & 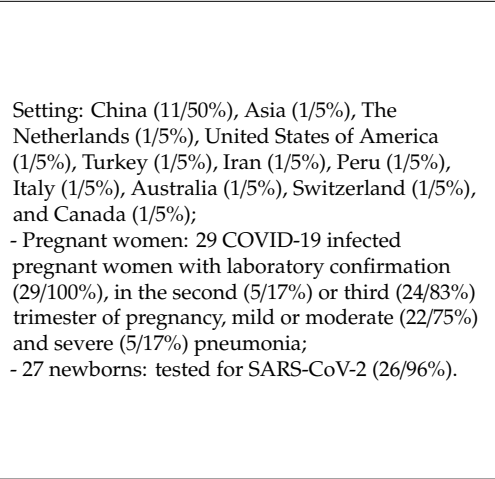 & 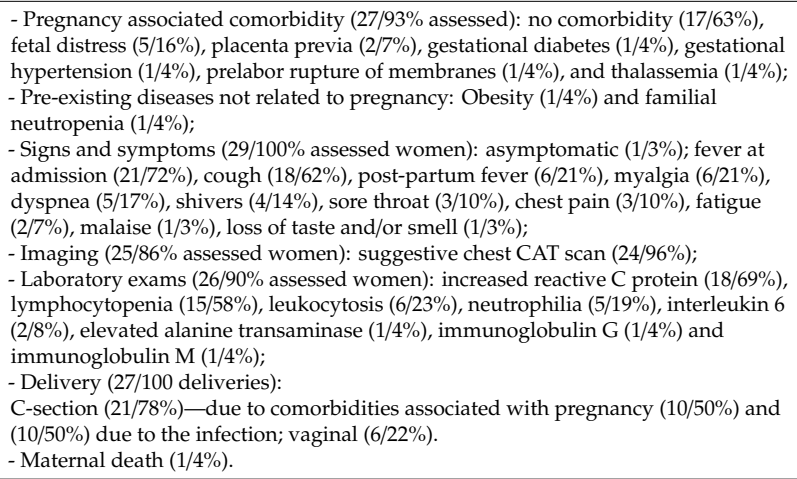 & $\begin{array}{l}-27 \text { newborns } \\
-24 \text { assessed: normal APGAR index (22/92\%), } \\
\text { normal weight }(18 / 75 \%) \text {, premature (10/41\%); } \\
-26 \text { newborns tested: negative for SARS-CoV-2 } \\
(24 / 92 \%) \text {; positive }(2 / 8 \%) ; \\
\text { - Neonatal death }(2 / 7 \%) ; \\
\text { - Isolation of mother and newborn }(13 / 48 \%) ; \\
\text { - Analysis of the placenta of } 6 \text { newborns: no } \\
\text { alterations infection-related }(6 / 100 \%) \text {. }\end{array}$ \\
\hline [34-52] & $\begin{array}{l}\text { Cross-sectional } \\
\text { Descriptive }\end{array}$ & 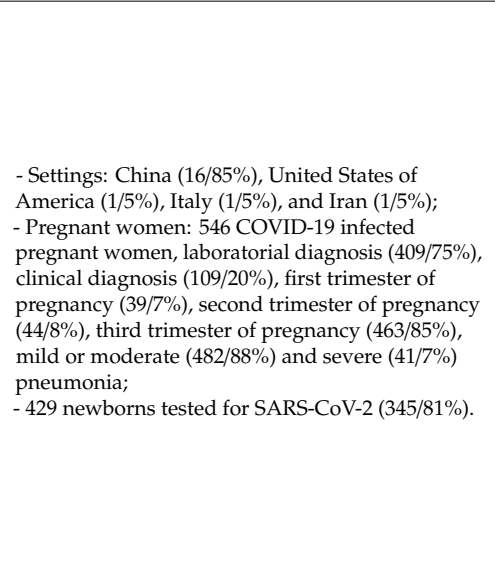 & 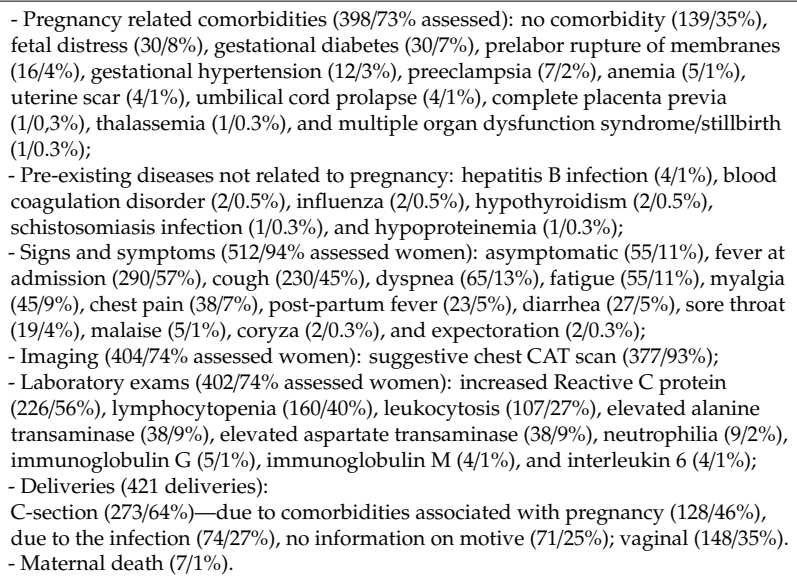 & $\begin{array}{l}\text { - Spontaneous abortion on the } 5 \text { th week of } \\
\text { pregnancy (1) } \\
-429 \text { newborns: normal APGAR index } \\
(417 / 97 \%), \text { premature }(74 / 17 \%) ; \\
\text { - Weight }(307 / 72 \%) \text { ) normal birth weight } \\
(292 / 95 \%), \text { low birth weight }(16 / 5 \%) ; \\
\text { - Newborns tested }(345 / 80 \%) \text { : SARS-CoV-2 } \\
\text { negative }(338 / 98 \%) \text {, positive }(7 / 2 \%) ; \\
\text { - Neonatal death: }(8 / 2 \%) ; \\
-107 \text { pregnant women assessed concerning } \\
\text { isolation of which } 97 \text { were isolated from } \\
\text { newborns; } \\
\text { - Analysis of the placenta of } 32 \text { newborns: no } \\
\text { alterations ( } 32 / 100 \%) \text {. }\end{array}$ \\
\hline
\end{tabular}


Table 2. Cont.

\begin{tabular}{|c|c|c|c|c|}
\hline Code & Study Design & Setting and Participants & Clinical, Laboratory and Imaging Findings of Women and Type of Delivery & Newborns' Clinical and Laboratory Findings \\
\hline [53-59] & Cross-sectional analytical & $\begin{array}{l}\text { - Setting: China }(6 / 86 \%) \text { and United States of } \\
\text { America }(1 / 14 \%) ; \text {; } 133 \text { COVID-19 infected } \\
\text { - Pregnant womenn: } \\
\text { pregnant women, laboratorial diagnosis }(104 / 78 \%), \\
\text { clinical diagnosis }(29 / 22 \%) \text {, first trimester of } \\
\text { pregnancy }(3 / 2 \%) \text {, second trimester of pregnancy } \\
(23 / 17 \%) \text {, third trimester of presnancy }(107 / 80 \%), \\
\text { mild or moderate pneumonia }(132 / 99 \%) \text {, or severe } \\
\text { pneumonia }(1 / 1 \%) ; \\
-108 \text { newborns tested for SARS-CoV-2 }(102 / 94 \%) .\end{array}$ & 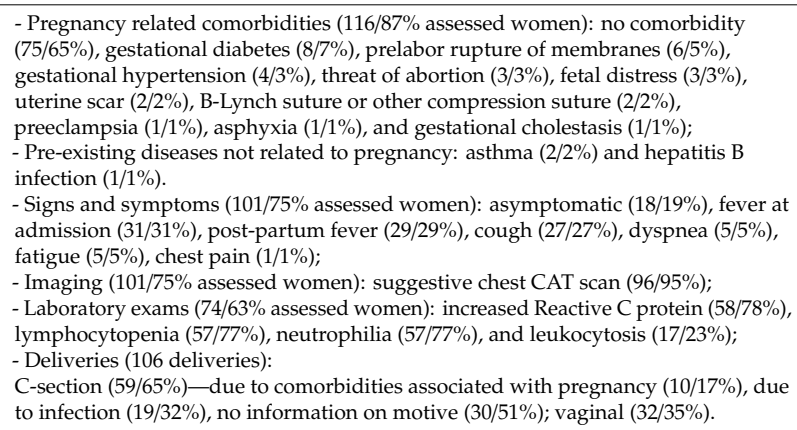 & $\begin{array}{l}\text { - } 108 \text { newborns: normal APGAR index } \\
(107 / 100 \%) ; \\
- \text { Weight }(71 / 76 \%) \text { : normal birth weight } \\
(65 / 92 \%) \text { and low birth weight }(6 / 8 \%) ; \\
\text { - Prematurity: premature }(8 / 7 \%) ; \\
\text { - Newborns tested }(102 / 94 \%) \text { : SARS-CoV-2 } \\
\text { negative test }(102 / 100 \%) ; \\
\text { - Neonatal death }(0) ; \\
\text { - } 23 \text { pregnant women were assessed concerning } \\
\text { isolation and } 20 \text { were isolated from newborns; } \\
\text { - Analysis of the placenta of } 16 \text { newborns: no } \\
\text { alterations (16/100\%). }\end{array}$ \\
\hline [60] & Case-control & $\begin{array}{l}\text { - Setting: China; } \\
\text { - Pregnant women: } 16 \text { pregnant women infected } \\
\text { by COVID-19, laboratory diagnosis }(16 / 100 \%) \text {, in } \\
\text { the third trimester of pregnancy }(16 / 100 \%) \text {, mild } \\
\text { or moderate pneumonia }(16 / 100 \%) ; \\
\text { - } 17 \text { newborns: tested for SARS-CoV-2 }(3 / 18 \%) \text {. }\end{array}$ & 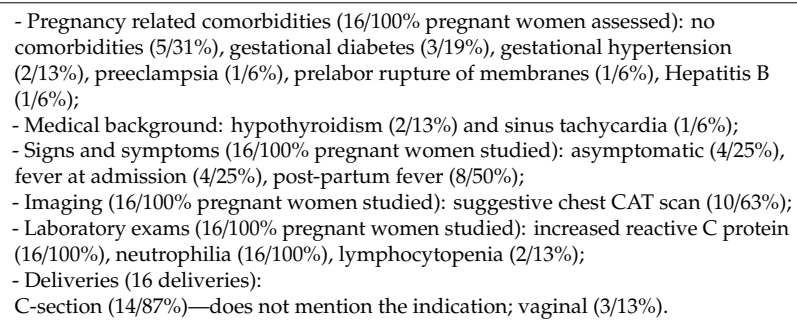 & $\begin{array}{l}\text { - } 17 \text { newborns: normal APGAR index } \\
(17 / 100 \%) \text {, normal weight }(14 / 82 \%) \text {, premature } \\
(3 / 18 \%) ; \\
\text { - Newborns tested (3/18\%): SARS-CoV-2 } \\
\text { negative }(3 / 100 \%) ; \\
\text { - Neonatal deaths }(0) ; \\
\text { - pregnant women assessed for isolation }(0) ; \\
\text { - Analysis of the placenta }(0) \text {. }\end{array}$ \\
\hline [61] & Cohort & $\begin{array}{l}\text { - Setting: China } \\
\text { - Pregnant women: } 31 \text { pregnant women infected } \\
\text { by COVID-19, laboratory diagnosis }(31 / 100 \%) \text {, in } \\
\text { the first trimester of pregnancy }(4 / 13 \%) \text {, in the } \\
\text { second trimester }(5 / 16 \%) \text {, in the third trimester } \\
(22 / 71 \%) \text {, mild or moderate pneumonia }(21 / 68 \%) \text {, } \\
\text { severe pneumonia }(10 / 32 \%) ; \\
\text { - } 17 \text { newborns tested for SARS-CoV-2 }(17 / 100 \%) \text {. }\end{array}$ & 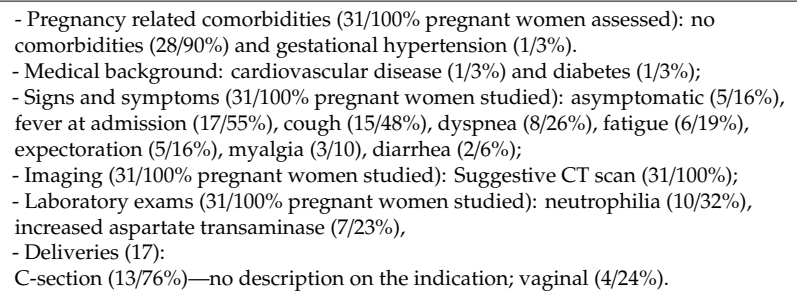 & $\begin{array}{l}\text { - } 17 \text { newborns: normal APGAR index }(16 / 94 \%) \\
\text { normal weight }(16 / 94 \%), \text { premature }(5 / 29 \%) ; \\
\text { - Newborns tested }(17 / 100 \%) \text { : SARS-CoV-2 } \\
\text { negative }(17 / 100 \%) ; \\
\text { - neonatal death }(0) ; \\
\text { - Pregnant women analyzed for isolation }(0) ; \\
\text { - Analysis of the placenta }(0) \text {. }\end{array}$ \\
\hline
\end{tabular}




\subsection{Findings from Case Reports}

The 21 case reports (42\%) [13-33] addressed 29 women in the second (17\%) and third trimester (83\%) of pregnancy, admitted with signs and symptoms of COVID-19 (97\%), later confirmed through RT-PCR (100\%). Twenty-two (75\%) developed mild to moderate pneumonia. The majority of the studies were conducted in China (50\%) [13-15,17,20-23,25,28,31] and presented limited description of the main features of the disease in positive, pregnant women. As for comorbidities, more than half of the women did not present any comorbidity (63\%) $[13,17,19,21-25,27-29,31]$. Among those with comorbidities, the most common was fetal distress $(16 \%)[16,20,22,23,32]$. The most frequent clinical signs and symptoms were fever (72\%) [13,14,16,19,22-31,33] and cough (62\%) [15,16,19-23,25-27,29,31-33]. Among the imaging findings, chest scans revealed pulmonary changes (96\%) [13-17,19-23,25-27,29-33]. Laboratory exams revealed increased reactive C protein $(69 \%)[14,15,17,19,20,23,25,27,29-31]$ and decreased lymphocytes (lymphocytopenia) (58\%) [13,14,17,19,20,22,23,26-29,31]. Twenty-seven infants were born from twenty-seven women, predominantly through C-section delivery $(78 \%)[13-17,20$ $23,25,26,28-30,33]$, there was medical indication to half of these due to maternal comorbidities [14$16,20,22,23,26,30]$ or infection $[13,17,20,23,25,28,29]$. Of the 27 newborns, two died [27,32], one of these died along with his/her mother, and 26 were tested for SARS-CoV-2: two tested positive [30,33]. In 13 cases (48\%), newborns were isolated from mothers [13,14,16,17,19-21,28,30,33], and, in six cases, the placenta was analyzed for pathological alterations $[13,17,32,33]$. There were no confirmed cases of vertical transmission.

\subsection{Findings from Descriptive Studies}

In cross-sectional descriptive studies (40\%) [34-52], 16 (85\%) were conducted in China [34-42, 44,46,47,49-52]. A total of 546 pregnant women were assessed for COVID-19, 409 (75\%) of whom were diagnosed with the disease through RT-PCR. The majority $(85 \%)$ was in the third trimester of pregnancy and had mild to moderate pneumonia (88\%). Most women did not present any comorbidity (35\%) [34-36,38-40,42,44-48,50,52]. The signs and symptoms more frequently found in pregnant women were fever [34-36,39-46,48-52] and cough [34-36,38-52]. Imaging findings revealed suggestive images of infection in 377 (93\%) pregnant women [35,42,44,46-48,50-52] and laboratory exams showed increased reactive C-protein (56\%) [35,36,38-42,44-51] and lymphocytopenia $(40 \%)$ [35,36,38-42,44-48,50,51]. A total of 421 pregnancies resulted in 429 newborns, with 8 twin births. C-section was the most frequent type of delivery (64\%), the majority resulting from pregnancy comorbidities $(46 \%)$ [34-36,38-43,45-47,50]. Six newborns died after birth [34,48] and two were stillbirths [42,48]. Seven mothers died from severe respiratory complications [48]. Three hundred and forty-five newborns were tested for SARS-CoV-2, seven of whom tested positive (2\%) [36,45-47]. In $97[43,45,46,52]$ cases, the newborns were isolated from their mothers. A total of 32 placentas were analyzed, with no abnormal findings [46].

\subsection{Findings from Cross-Sectional Analytical Studies}

Concerning the cross-sectional analytical studies (14\%) [53-59], six were conducted in China $(86 \%)$ and one was conducted in the United States of America (14\%). A total of 133 pregnant women were infected with COVID-19, confirmed through laboratory (78\%) and clinical diagnosis (22\%). Most pregnant women were in their third trimester $(80 \%)$ and had developed mild to moderate pneumonia (99\%). Clinical findings showed that only 41 (35\%) [54-57,59] women had some comorbidity (Table 2). The most common signs and symptoms were fever at admission [55-59], postpartum fever [54,57,58], and cough [54-56,58].

Chest CT scan was suggestive in 96 (95\%) women [54-58] and laboratory exams revealed increased reactive C protein (78\%) [54-56], lymphocytopenia (77\%) [54-56], and neutrophilia (77\%) [54,56]. Of the 106 women, $59(65 \%)$ had a C-section, 19 of whom due to COVID-19 [53,57]. A total of 108 babies were born, with two sets of twins. Eighty-seven (94\%) were tested for SARS-CoV-2, and all were 
negative. Twenty-three pregnant women were isolated from their newborns $[55,58]$. There were no neonatal deaths; 16 placentas were analyzed, and no pathognomonic features were identified. Vertical transmission was not confirmed.

\subsection{Findings from Longitudinal Studies}

The case-control study (2\%) [60] was conducted using the medical records of pregnant women admitted to a hospital in China. The study compares the clinical features, maternal and neonatal outcomes of 16 pregnant women with COVID-19, and 18 without the disease, but suspected of being infected. The study does not clearly report criteria for including participants in the case or control groups. The description in Table 2 refers to COVID-19 infected pregnant women. All 16 women were in their third trimester of pregnancy, $5(31 \%)$ of whom had no pregnancy-related comorbidities. The most frequent symptom was fever at admission (25\%) and after birth (50\%). Ten women had suggestive CT scans, and there was an increase in reactive $C$ protein and neutrophilia in all women studied. Fourteen $(87 \%)$ women had a C-section, but the study does not report why a C-section was indicated. A total of 17 babies were born, with one set of twins, with no complications. Only three newborns were tested for SARS-CoV-2 and were negative. Isolation measures after birth or analysis of the placenta were not reported.

The cohort study (2\%) [61], also conducted in China, retrospectively describes 31 pregnant women and 35 non-pregnant women with COVID-19. Only the clinical findings of pregnant women are described. In total, 31 pregnant women were assessed. The majority was in the third trimester of pregnancy $(71 \%)$, all had confirmation of diagnosis through RT-PCR, $21(68 \%)$ developed mild to moderate pneumonia, and 10 had severe pneumonia. Twenty-eight did not present comorbidities during pregnancy. The most prevalent signs and symptoms were fever $(55 \%)$ and cough $(48 \%)$. The chest CT scan was suggestive in all cases, and abnormal laboratory tests were related to the increased number of neutrophils (32\%), aspartate transaminase $(26 \%)$, and interleukin 6 . There were 17 deliveries, 13 (76\%) of which were C-sections, though the authors do not report why C-sections were indicated. A total of 17 single, healthy fetuses were born and tested negative for SARS-CoV-2. No report is provided on the isolation measures adopted between mothers and babies after delivery and there was no evaluation of placentas.

\section{Discussion}

This review was intended to answer a question concerning the effects of COVID-19 infection during pregnancy and neonatal prognosis. Forty-nine studies were eligible and included case reports, cross-sectional, analytical cross-section, case-control, and cohort presenting low levels of evidence. The low levels of evidence are due to the novelty of the COVID-19 pandemic and the need for rapidly acquiring knowledge to support public policies. As the number of cases increases worldwide, evidence about the impact of this virus during pregnancy for both women and newborns is expected to become stronger, especially with the development of more robust comparative studies and follow-up with control groups.

\subsection{Characterization of Pregnant Women}

A total of 755 pregnant women were assessed, 635 were from China [13-15,17,20-23,25,28,31, 34-42,44,46,47,49-58,60,61], 60 from the USA [19,42,59], 42 from Italy [45], 10 from Iran [27,49], and one pregnant woman in Asia [16], Honduras [18], Australia [24], Turkey [26], Spain [29], Peru [30], Switzerland [32], and Canada [33], respectively. All women evaluated were in the fertile period, while there were pregnant women in the first trimester $(46 / 6 \%)$, in the second trimester $(77 / 10 \%)$ and in the third trimester of pregnancy $(632 / 84 \%)$, which is why only 598 infants were born in the period.

The fact that most pregnant women were from China imposes limitations on interpreting the evidence, considering cultural and epidemiological differences when compared with pregnant women 
from other countries and cultures. However, even in the minority $(120 / 16 \%)$, non-Chinese pregnant women were evaluated, and the characteristics (clinical and epidemiological) showed no differences.

Regarding the pregnant women's age, fertile period, and length of pregnancy, the studies analyzed showed a wide variation and a lack of evidence of infection by SARS-CoV-2 during the first and second trimester of pregnancy. It can be inferred that, according to the low prevalence of severe infection among pregnant women (57/8\%), many of them could be asymptomatic and/or with mild symptoms, without the need for hospital care, corroborating findings from previous viral pandemics [62].

In view of the limited data regarding the Middle East Respiratory Syndrome (MERS), a systematic review with meta-analysis recovered seven studies that did not report spontaneous abortion. The rate of premature birth was $32.1 \%$ ( 3 of 11), all occurring before 34 weeks of gestation. Preeclampsia was described in $19.1 \%$ ( 1 of 7$)$; however, no cases of premature rupture of membranes or restricted fetal growth were reported. The rates of C-sections and perinatal death were $61.8 \%$ (5 of 8 ) and $33.2 \%$ ( 3 of 10), respectively, including two stillbirths and one neonatal death ( $4 \mathrm{~h}$ after the birth of an extremely premature baby). There were no reports of fetal distress, Apgar score $<7$ at $5 \mathrm{~min}$, neonatal asphyxia, or admission to the neonatal intensive care unit (ICU). Finally, signs of vertical transmission were not found during the follow-up period in any of the newborns [63].

According to the above, it appears that the scarce data on infection with the new coronavirus in early pregnancy may be related, but not limited, to the absence of tests performed during this period, since asymptomatic cases may go unnoticed due to poorer surveillance of pregnancy because of restrictions, on the part of medical staff or the pregnant women themselves, to attend appointments within a hospital setting. Thus, we suggest that tests for COVID-19 should be routinely performed in prenatal care.

\subsection{Clinical Findings in Pregnant Women}

About diagnosis, this study verifies that of the 728 pregnant women evaluated, 589 (81\%) and 139 (19\%) were diagnosed by Reverse Transcription followed by Polymerase Chain Reaction (RT-PCR) and by clinical assessment, respectively. The gold standard for diagnosing Covid-19 is tissue culture in which the antigen is isolated, using Polymerase Chain Reaction (PCR), which detects nucleic acid. Even so, a single result not detected through RT-PCR for SARS-CoV-2 does not exclude a COVID-19 diagnosis, as there are various factors, such as inadequate sample collection, type of biological sample, the time elapsed between sample collection and onset of symptoms, and fluctuation of viral load, that may influence a test's result. For this reason, an RT-PCR test should be repeated in another sample of a patient's respiratory tract whenever there are discordances between results and epidemiological conditions, especially in populations where a false-positive may result in disastrous consequences.

The presence of comorbidities related to pregnancy does not seem to directly influence the adverse outcomes of pregnant women and their newborns, as the two neonatal deaths were of mothers without comorbidities, but who, for some reason, developed severe pneumonia. However, it is observed that gestational diabetes and fetal distress were the most prevalent comorbidities, showing that the conditions of the fetus should be carefully evaluated, especially in those asymptomatic and without comorbidities. Thus, the absence of comorbidities may directly influence the care provided and attention paid by professionals to pregnant women, exposing some of them to a worse prognosis [64].

Concerning the signs and symptoms of infection at the time of admission, 689 (91\%) pregnant women were evaluated [13-61], and the main signs and symptoms presented were fever at admission $(363 / 53 \%)$, cough $(290 / 42 \%)$, and dyspnea $(83 / 12 \%)$. It is remarkable that $83(12 \%)$ of pregnant women were asymptomatic but were tested (through RT-PCR to detect SARS-CoV-2) due to exposure to people diagnosed with COVID-19, reinforcing the need to follow recommendations provided by the Centers for Disease Control and Prevention (CDCs) to testing risk groups in contact with those diagnosed with COVID-19, [65] though this approach may not be feasible in some contexts where there is a shortage of tests. 
Regarding imaging tests, chest CT scans were performed in 577 (76\%) pregnant women [13-61], with $538(93 \%)$ pregnant women showing changes suggestive of infection [13-17,19-23,25-27,29-33, $35,42,44,48,50-52,55-58,60,61]$. CT scans were very useful in the initial assessment at the time of admission. The most prevalent changes were in the findings of $C$-reactive protein, which was above the normal range $[14,15,17,19,20,23,25,27,29-31,35,36,38-42,44,45,48-51,60]$, and lymphocytopenia [13, $14,17,19,20,22,23,26-29,31,35,36,38-42,44,45,48,50,51,60]$. It is outstanding that these changes in CT scans and laboratory findings are reported in studies with the general population [66]. Concerning the evaluation of imaging tests, whether they are chest X-rays or chest CT scans, these can assist in the diagnosis of the disease; however, they should not be taken as conclusive evidence for confirming or excluding SARS-CoV-2 infection. The reason is that different bacterial and viral etiologic agents cause pulmonary infections. Thus, imaging tests such as chest CT scans, widely used during emerging respiratory outbreaks or as in the case of the pandemic currently established by COVID-19, have high sensitivity, but low specificity. Despite limitations, these tests should be used to screen, evaluate, and monitor this kind of infection [67].

\subsection{Childbirth}

Overall, 587 childbirths were reported, with more than half of the pregnant women having C-sections $(379 / 65 \%)$. When checking the indications for the C-sections, pregnancy-related comorbidities were the cause for performing C-sections in 148 pregnant women; in the case of 103, the indication was infection, and in 128 cases, indications were not reported. No details were provided when the indication for a C-section was the infection. In most cases, the time of delivery was determined by obstetric reasons, rather than the maternal diagnosis of COVID-19 [68].

The decision for the type of delivery is usually more frequently influenced by the presence of maternal and/or fetal impairment. When there were imminent risks, an emergency C-section was the alternative chosen, which has happened in the case of SARS-CoV-2 infections in which the pregnant woman's clinical condition is complex. However, in the presence of COVID-19, the threshold for C-sections became lower than usual so that infection control procedures could be more easily adhered to and the transmission of the disease to the fetus is minimized [69].

\subsection{Newborns}

Regarding the characteristics of the newborns, 598 babies were born, with 590 single births and eight twins. A total of 493 (82\%) newborns were tested for SARS-CoV-2, nine (2\%) of whom tested positive, $101(20 \%)$ were premature, and $28(6 \%)$ were born underweight $(<2500 \mathrm{~g})$. Ten neonatal deaths $[27,32,34,42,48]$ and one spontaneous abortion [42] were reported. Isolation measures were established between 130 mothers and their newborns, while no pathognomonic changes (indicative of disease) were found in the 54 placental samples assessed.

Note that most of the newborns did not present serious complications. The unfavorable outcomes refer to ten neonatal deaths, one spontaneous abortion, eight maternal deaths, one stillbirth, nine $(2 \%)$ positive SARS-CoV-2 tests, and three newborns with high rates of IgG and IgM antibodies against SARS-CoV-2.

Regarding the nine newborns who tested positive for SARS-CoV-2, three tested positive $[33,48]$ immediately after delivery, but then tested negative $24 \mathrm{~h}$ after delivery. Another newborn tested positive $36 \mathrm{~h}$ after delivery [36]. It is important to note that whether the mothers and babies in these three cases were isolated after delivery is not reported, making it difficult to establish the transmission routes, according to the authors, in addition to the absence of intrauterine tissue and amniotic fluid samples.

Two newborns tested positive for the new coronavirus after being breastfed by their mothers without wearing masks, as the maternal infection was not known in the postpartum period. However, vertical transmission could not be confirmed or ruled out, as the authors stressed that the newborns were not tested for COVID-19 immediately after birth. Moreover, in this same study, a pregnant woman with COVID-19 gave birth to a newborn by vaginal delivery, who tested positive for SARS-CoV-2 
despite the mother wearing a surgical mask and the medical team wearing proper PPE throughout labor [45]. In another study [70], a possible transmission through breast milk was raised by the detection of viral RNA in the milk of one of the pregnant women and subsequent confirmation of contamination of the baby, although the mother followed safety precautions when breastfeeding the child. This reinforces the need for testing mothers before giving birth, using proper vestments (staff and mother), and avoiding breastfeeding when testing is not possible.

The other two newborns tested positive $16 \mathrm{~h} \mathrm{[30]} \mathrm{and} 53 \mathrm{~h} \mathrm{[46]} \mathrm{after} \mathrm{delivery,} \mathrm{respectively.}$ Both studies reported the followed guidelines were observed: the use of masks by the mother, the entire medical team was attired, mother and baby were isolated after delivery, and no breastfeeding. The authors, however, reported an important limitation of the study, the absence of complementary assessments (presence of viruses in amniotic fluid, umbilical cord blood, or placental tissue). Two out of the nine positive babies were intubated [30,45], and three had mild pneumonia [36,46,47], although they fully recovered within a few days.

Dong et al. [28] reported the case of a newborn who, shortly after birth, presented leukocytosis and a high rate of IgG and IgM antibodies against SARS-CoV-2 and IL-6 cytokines. The baby, however, presented no symptoms and tested negative for the virus. Although the newborn tested negative for SARS-CoV-2, the authors stated that the high rate of IgM antibodies within $2 \mathrm{~h}$ after birth suggested the occurrence of intrauterine infection, as there would be no transfer of these antibodies from the mother to the fetus through the placenta due to the size of this macromolecule. Additionally, in general, these take three to seven days to be produced by the body after contact with the infectious agent. The authors, however, do not rule out the possibility of infection during delivery.

Zeng et al. [35] described similar results regarding the assessment of the presence of specific antibodies against SARS-CoV-2 in the blood of newborns from mothers with confirmed COVID-19 infection. Two babies presented rates of IgG and IgM antibodies specific to the virus above the normal level, but none showed symptoms of the infection. The authors of this study stressed the possibility that the newborn developed IgM antibodies during the gestational period if the virus had crossed the placental barrier.

\subsection{Limitations}

The studies recovered in this review have several limitations. Among them, small sample sizes, retrospective evaluation of medical records with incomplete data, as well as the low number of babies tested for SARS-COV-2, compared to the number of births.

Among this review's limitations, we highlight the possibility that the same patients are reported more than once, as they may have been included in different studies and we addressed secondary data only. Most of the cases reported refer to Chinese pregnant women and there was a lack of a standard assessment in newborns to verify the presence of viruses in amniotic fluid, umbilical cord blood or placental tissue. There was also little information about the care provided during delivery and postpartum, and an absence of clear inclusion criteria for the control group. Nonetheless, despite these limitations, this review has strengths, such as presenting a comparison of all studies available so far, compiling scattered data and grouping them more clearly in order to make analyses and inferences, and, based on what was assessed, reporting that there is no evidence of vertical transmission thus far, as there are knowledge gaps concerning the care provided during and after delivery, and a lack of suitable biological samples for testing SARS-CoV-2.

\section{Conclusions}

The results show that the potential worsening of the women infected with SARS-CoV-2 cannot be ruled out, whether the infection is associated with comorbidities or not. As documented here, there is a risk of women developing respiratory disorders or having cardiac rhythm disturbances or acid-base imbalance, among others. The risk of postpartum hemorrhage and premature delivery is significant, which is why C-sections were widely used. Relentless monitoring is recommended for 
pregnant women who report signs and symptoms suggested of COVID-19, especially at a time when women in countries with radical isolation measures have difficulty attending regular prenatal care. Those who cannot be tested before delivery should avoid having contact with the baby and wear masks to decrease the spread of the disease.

Regarding the risk for babies, there is no concrete evidence of vertical transmission, though one cannot discard this possibility. Nonetheless, cases of respiratory diseases, abnormal Apgar indexes, and mild pneumonia were reported. Fortunately, all the babies who tested positive for the infection recovered fully and rapidly. A rigorous assessment of the newborns' clinical signs is recommended, as well as chest CT scans, within three days after birth.

Author Contributions: Á.F.L.d.S., H.E.F.d.C., L.B.d.O., G.S., and I.F. had the idea for and designed the study and had full access to all of the data in the study and take responsibility for the integrity of the data and the accuracy of the data analysis. Á.F.L.d.S., H.E.F.d.C., L.B.d.O., G.S., I.F., E.L.S.C., E.W., D.d.A., A.F.C.F., and I.A.C.M. did the analysis, and all authors critically revised the manuscript for important intellectual content. All authors gave final approval for the version to be published. All authors agree to be accountable for all aspects of the work in ensuring that questions related to the accuracy or integrity of any part of the work are appropriately investigated and resolved. All authors have read and agreed to the published version of the manuscript.

Funding: Coordination for the Improvement of Higher Education Personnel (CAPES-Brazil) and National Council for Scientific and Technological Development (CNPq-Brazil).

Conflicts of Interest: The authors no reported conflict of interest.

\section{References}

1. Lai, C.C.; Shih, T.P.; Ko, W.C.; Tang, H.J.; Hsueh, P.R. Severe acute respiratory syndrome coronavirus 2 (SARS-CoV-2) and coronavirus disease-2019 (COVID-19): The epidemic and the challenges. Int. J. Antimicrob. Agents 2020, 55, 105924. [CrossRef] [PubMed]

2. WHO. Coronavirus Disease 2019 (COVID-19). Situation Report-80. Available online: https://www.who.int/ docs/default-source/coronaviruse/situation-reports/20200409-sitrep-80-covid-19.pdf?sfvrsn=1b685d64_2 (accessed on 10 May 2020).

3. Centers for Disease Control and Prevention (CDC). Coronavirus. Available online: https://www.cdc.gov/ coronavirus/index.html (accessed on 10 May 2020).

4. Perlman, S. Another decade, another coronavirus. N. Engl. J. Med. 2020, 882, 760-762. [CrossRef] [PubMed]

5. Chen, N.; Zhou, M.; Dong, X.; Qu, J.; Gong, F.; Han, Y.; Qiu, Y.; Wang, J.; Liu, Y.; Wei, Y.; et al. Epidemiological and clinical characteristics of 99 cases of 2019 novel coronavirus pneumonia in Wuhan, China: A descriptive study. Lancet 2020, 395, 507-513. [CrossRef]

6. Huang, C.; Wang, Y.; Li, X.; Ren, L.; Zhao, J.; Hu, Y.; Zhang, L.; Fan, G.; Xu, J.; Gu, X.; et al. Clinical feature of patients infected with 2019 novel coronavirus in Wuhan, China. Lancet 2020, 395, 497-506. [CrossRef]

7. Kourtis, A.P.; Read, J.S.; Jamieson, D.J. Pregnancy and infection. N. Engl. J. Med. 2014, 370, 2211-2218. [CrossRef]

8. Wang, D.; Hu, B.; Hu, C.; Zhu, F.; Liu, X.; Zhang, J.; Wang, B.; Xiang, H.; Cheng, Z.; Xiong, Y.; et al. Clinical characteristics of 138 hospitalized patients with 2019 novel coronavirus-infected pneumonia in Wuhan, China. JAMA 2020, 323, 1061-1069. [CrossRef]

9. Qiao, J. What are the risks of COVID-19 infection in pregnant women? Lancet 2020, 395, 760-762. [CrossRef]

10. Kontou, P.I.; Braliou, G.G.; Dimou, N.L.; Nikolopoulos, G.; Bagos, P.G. Antibody Tests in Detecting SARS-CoV-2 Infection: A Meta-Analysis. Diagnostics 2020, 10, 319. [CrossRef]

11. Peters, M.D.; Godfrey, C.M.; McInerney, P.; Soares, C.B.; Khalil, H.; Parker, D. Methodology for JBI scoping reviews. In The Joanna Briggs Institute Reviewers' Manual 2015; The Joanna Briggs Institute: Adelaide, Australia, 2015.

12. Moher, D.; Liberati, A.; Tetzlaff, J.; Altman, D. Preferred reporting items for systematic reviews and meta-analyses: The PRISMA statement. PLoS Med. 2009, 6, e1000097. [CrossRef] [PubMed]

13. Fan, C.; Lei, D.; Fang, C.; Li, C.; Wang, M.; Liu, Y.; Bao, Y.; Sun, Y.; Huang, J.; Guo, Y.; et al. Perinatal Transmission of COVID-19 Associated SARS-CoV-2: Should We Worry? Clin. Infect. Dis. 2020, ciaa226. [CrossRef] 
14. Chen, S.; Huang, B.; Luo, D.J.; Li, X.; Yang, F.; Zhao, Y.; Nie, X.; Huang, B.X. Pregnant women with new coronavirus infection: A clinical characteristics and placental pathological analysis of three cases. Zhonghua Bing Li Xue Za Zhi 2020, 49, E005.

15. Li, Y.; Zhao, R.; Zheng, S.; Chen, X.; Wang, J.; Sheng, X.; Zhou, J.; Cai, H.; Fang, Q.; Fu, F.; et al. Lack of Vertical Transmission of Severe Acute Respiratory Syndrome Coronavirus 2, China. Emerg Infect Dis. 2020, 26. [CrossRef] [PubMed]

16. Lee, D.H.; Lee, J.; Kim, E.; Woo, K.; Park, H.; An, J. Emergency cesarean section on severe acute respiratory syndrome coronavirus 2 (SARS- CoV-2) confirmed patient. Korean J. Anesth. 2020, in press. [CrossRef]

17. Wang, X.; Zhou, Z.; Zhang, Z.; Zhu, F.; Tang, Y.; Shen, X. A case of 2019 Novel Coronavirus in a pregnant woman with preterm delivery. Clin. Infect. Dis. 2020. [CrossRef] [PubMed]

18. Zambrano, L.; Fuentes-Barahona, I.C.; Bejarano-Torres, D.A.; Bustillo, C.; Gonzales, G.; Vallecillo-Chinchilla, G.; Sanchez-Martínez, F.E.; Valle-Reconco, J.A.; Sierra, M.; Bonilla-Aldana, D.K. A pregnant woman with COVID-19 in Central America. Travel Med. Infect. Dis. 2020, 101639. [CrossRef] [PubMed]

19. Iqbal, S.N.; Overcash, R.; Mokhtari, N.; Saeed, H.; Gold, S.; Auguste, T.; Mirza, M.U.; Ruiz, M.E.; Chahine, J.J.; Waga, M.; et al. An Uncomplicated Delivery in a Patient with Covid-19 in the United States. N. Engl. J. Med. 2020, 382, e34. [CrossRef]

20. Kang, X.; Zhang, R.; He, H.; Yao, Y.; Zheng, Y.; Wen, X.; Zhu, S. Anesthesia management in cesarean section for a patient with coronavirus disease 2019. J. Zhejiang Univ. 2020, 49, $249-252$.

21. Lu, D.; Sang, L.; Du, S.; Li, T.; Chang, Y.; Yang, X. Asymptomatic COVID-19 infection in late pregnancy indicated no vertical transmission. J. Med. Virol. 2020, 1-5. [CrossRef] [PubMed]

22. Liao, X.; Yang, H.; Kong, J.; Yang, H. Chest CT Findings in a Pregnant Patient with 2019 Novel Coronavirus Disease. Balkan Med. J. 2020, in press. [CrossRef] [PubMed]

23. Buonsenso, D.; Raffaelli, F.; Tamburrini, E.; Biasucci, D.G.; Salvi, S.; Smargiassi, A.; Inchingolo, R.; Scambia, G.; Lanzone, A.; Testa, A.C.; et al. Clinical role of lung ultrasound for the diagnosis and monitoring of COVID-19 pneumonia in pregnant women. Ultrasound Obstet Gynecol. 2020, in press. [CrossRef]

24. Lowe, B.; Bopp, B. COVID-19 vaginal delivery-A case report. Aust. N. Z. J. Obstet. Gynaecol. 2020, in press. [CrossRef] [PubMed]

25. Khan, S.; Peng, L.; Siddique, R.; Nabi, G.; Nawsherwan; Xue, M.; Liu, J.; Han, G. Impact of COVID-19 infection on pregnancy outcomes and the risk of maternal-to-neonatal intrapartum transmission of COVID-19 during natural birth. Infect. Control Hosp. Epidemiol. 2020, in press. [CrossRef] [PubMed]

26. Kalafat, E.; Yaprak, E.; Cinar, G.; Varli, B.; Ozisik, S.; Uzun, C.; Azap, A.; Koc, A. Lung ultrasound and computed tomographic findings in pregnant woman with COVID-19. Ultrasound Obs. Gynecol. 2020, in press. [CrossRef]

27. Karami, P.; Naghavi, M.; Feyzi, A.; Aghamohammadi, M.; Novin, M.S.; Mobaien, A.; Qorbanisani, M.; Karami, A.; Norooznezhad, A.H. Mortality of a pregnant patient diagnosed with COVID-19: A case report with clinical, radiological, and histopathological findings. Travel Med. Infect. Dis. 2020, in press. [CrossRef]

28. Dong, L.; Tian, J.; He, S.; Zhu, C.; Wang, J.; Liu, C.; Yang, J. Possible Vertical Transmission of SARS-CoV-2 From an Infected Mother to Her Newborn. JAMA 2020, in press. [CrossRef] [PubMed]

29. González, R.; Ocampo, P.J.; González, B.L.; Santana-Cabrera, L. Pregnancy and perinatal outcome of a woman with COVID-19 infection. Rev. Clin. Esp. 2020, in press.

30. Alzamora, M.C.; Paredes, T.; Caceres, D.; Webb, C.M.; Valdez, L.M.; Rosa, M.L. Severe COVID-19 during Pregnancy and Possible Vertical Transmission. Am. J. Perinatol. 2020, in press.

31. Xiong, X.; Wei, H.; Zhang, Z.; Chang, J.; Ma, X.; Gao, X.; Chen, Q.; Pang, Q. Vaginal delivery report of a healthy neonate born to a convalescent mother with COVID-19. J. Med. Virol. 2020, in press.

32. Baud, D.; Greub, G.; Favre, G.; Gengler, C.; Jaton, K.; Dubruc, E.; Pomar, L. Second-Trimester Miscarriage in a Pregnant Woman With SARS-CoV-2 Infection. JAMA 2020, e207233, in press. [CrossRef] [PubMed]

33. Kirtsman, M.; Diambomba, Y.; Poutanen, S.M.; Malinowski, A.K.; Vlachodimitropoulou, E.; Parks, W.T.; Erdman, L.; Morris, S.K.; Shah, P.S. Probable congenital SARS-CoV-2 infection in a neonate born to a woman with active SARS-CoV-2 infection. CMAJ 2020, in press. [CrossRef]

34. Liu, Y.; Chen, H.; Tang, K.; Guo, Y. Clinical manifestations and outcome of SARS-CoV-2 infection during pregnancy. J. Infect. 2020, piiS0163-4453, 30109-2, in press. [CrossRef] [PubMed] 
35. Chen, H.; Guo, J.; Wang, C.; Luo, F.; Yu, X.; Zhang, W.; Li, J.; Zhao, D.; Xu, D.; Gong, Q.; et al. Clinical characteristics and intrauterine vertical transmission potential of COVID-19 infection in nine pregnant women: A retrospective review of medical records. Lancet 2020, 395, 809-815. [CrossRef]

36. Yu, N.; Li, W.; Kang, Q.; Xiong, Z.; Wang, S.; Lin, X.; Liu, Y.; Xiao, J.; Liu, H.; Deng, D.; et al. Clinical features and obstetric and neonatal outcomes of pregnant patients with COVID-19 in Wuhan, China: A retrospective, single-centre, descriptive study. Lancet Infect. Dis. 2020, 20, 559-564, in press. [CrossRef]

37. Zeng, H.; Xu, C.; Fan, J.; Tang, Y.; Deng, Q.; Zhang, W.; Long, X. Antibodies in Infants Born to Mothers With COVID-19 Pneumonia. JAMA 2020, in press. [CrossRef]

38. Chen, S.; Liao, E.; Shao, Y. Clinical analysis of pregnant women with 2019 novel coronavirus pneumonia. J. Med. Virol. 2020, in press. [CrossRef] [PubMed]

39. Liu, D.; Li, L.; Wu, X.; Zheng, D.; Wang, J.; Yang, L.; Zheng, C. Pregnancy and Perinatal Outcomes of Women With Coronavirus Disease (COVID-19) Pneumonia: A Preliminary Analysis. Am. J. Roentgenol. 2020, 18, 1-6, in press. [CrossRef]

40. Zhu, H.; Wang, L.; Fang, C.; Peng, S.; Zhang, L.; Chang, G.; Xia, S.; Zhou, W. Clinical analysis of 10 neonates born to mothers with 2019-nCoV pneumonia. Transl. Pediatr. 2020, 9, 51-60. [CrossRef]

41. Chen, L.; Qin, L.; Zheng, D.; Jiang, H.; Wei, Y.; Zou, L.; Feng, L.; Xiong, G.; Sun, G.; Wang, H.; et al. Clinical Characteristics of Pregnant Women with Covid-19 in Wuhan, China. N. Engl. Med. 2020, 1-3. [CrossRef]

42. Yan, J.; Guo, J.; Fan, C.; Juan, J.; Yu, X.; Li, J.; Feng, L.; Li, C.; Chen, H.; Qiao, Y.; et al. Coronavirus disease 2019 (COVID-19) in pregnant women: A report based on 116 cases. Am. J. Obs. Gynecol. 2020, in press. [CrossRef]

43. Breslin, N.; Baptiste, C.; Gyamfi-Bannerman, C.; Miller, R.; Martinez, R.; Bernstein, K.; Ring, L.; Landau, R.; Purisch, S.; Friedman, A.M.; et al. COVID-19 infection among asymptomatic and symptomatic pregnant women: Two weeks of confirmed presentations to an affiliated pair of New York City hospitals. Am. J. Obs. Gynecol. MFM 2020, in press. [CrossRef]

44. Chen, R.; Zhang, Y.; Huang, L.; Cheng, B.; Xia, Z.; Meng, Q. Safety and efficacy of different anesthetic regimens for parturients with COVID-19 undergoing Cesarean delivery: A case series of 17 patients. Can. J. Anaesth. 2020, in press. [CrossRef] [PubMed]

45. Ferrazi, E.; Frigerio, L.; Savasi, V.; Vergani, P.; Prefumo, F.; Barresi, S.; Bianchi, S.; Ciriello, E.; Facchinetti, F.; Gervasi, M.T.; et al. Vaginal delivery in SARS-CoV-2 infected pregnant women in Northern Italy: A retrospective analysis. BJOG 2020, in press. [CrossRef] [PubMed]

46. Nie, R.; Wang, S.; Yang, Q.; Fan, C.; Liu, Y.; He, W.; Jiang, M.; Liu, C.; Zeng, W.; Wu, J.; et al. Clinical features and the maternal and neonatal outcomes of pregnant women with coronavirus disease 2019. medRxiv 2020. [CrossRef]

47. Khan, S.; Jun, L.; Nawsherwan; Siddique, R.; Li, Y.; Han, G.; Xue, M.; Nabi, G.; Liu, J. Association of COVID-19 with pregnancy outcomes in health-care workers and general women. Clin. Microbiol. Infect. 2020, in press. [CrossRef] [PubMed]

48. Hantoushzadeh, S.; Shamshirsaz, A.A.; Aleyasin, A.; Seferovic, M.D.; Aski, S.K.; Arian, S.E.; Pooransari, P.; Ghotbizadeh, F.; Aalipour, S.; Soleimani, Z.; et al. Maternal Death Due to COVID-19 Disease. Am. J. Obstet. Gynecol. 2020, in press. [CrossRef]

49. Xu, Q.; Shen, J.; Pan, L.; Lei, H.; Jiang, X.; Lu, W.; Yang, G.; Li, S.; Wang, Z.; Xiong, G.; et al. Coronavirus disease 2019 in pregnancy. Int. J. Infect. Dis. 2020, 95, 376-383.

50. Wu, Y.; Liu, C.; Dong, L.; Zhang, C.; Chen, Y.; Liu, J.; Zhang, C.; Duan, C.; Zhang, H.; Mol, B.W.; et al. Coronavirus disease 2019 among pregnant Chinese women: Case series data on the safety of vaginal birth and breastfeeding. BJOG 2020, in press. [CrossRef]

51. Yang, H.; Hu, B.; Zhan, S.; Yang, L.; Xiong, G. Effects of SARS-CoV-2 infection on pregnant women and their infants: A retrospective study in Wuhan, China. Arch. Pathol. Lab. Med. 2020, in press. [CrossRef]

52. Liu, W.; Wang, J.; Li, W.; Zhou, Z.; Liu, S.; Rong, Z. Clinical characteristics of 19 neonates born to mothers with COVID-19. Front. Med. 2020, 14, 193-198. [CrossRef]

53. Zhang, L.; Jiang, Y.; Wai, M.; Cheng, B.; Zhou, X.; Li, J.; Tian, J.; Dong, L.; Hu, R. Analysis of the pregnancy outcomes in pregnant women with COVID-19 in Hubei Province. Zhonghua Fu Chan Ke Za Zhi 2020, 55, E009.

54. Liu, H.; Liu, F.; Li, J.; Zhang, T.; Wang, D.; Lan, W. Clinical and CT imaging features of the COVID-19 pneumonia: Focus on pregnant women and children. J. Infect. 2020, 80, E7-E13, in press. [CrossRef] 
55. Liao, J.; He, X.; Gong, Q.; Yang, L.; Zhou, C.; Li, J. Analysis of vaginal delivery outcomes among pregnant women in Wuhan, China during the COVID-19 pandemic. Int. J. Gynaecol. Obs. 2020, in press. [CrossRef] [PubMed]

56. Wu, X.; Sun, R.; Chen, J.; Xie, Y.; Zhang, S.; Wang, X. Radiological findings and clinical characteristics of pregnant women with COVID-19 pneumonia. Int. J. Gynaecol. Obs. 2020, in press. [CrossRef]

57. Yue, L.; Han, L.; Li, Q.; Zhong, M.; Wang, J.; Wan, Z.; Chu, C.; Zeng, Y.; Peng, M.; Yang, L.; et al. Anaesthesia and infection control in cesarean section of pregnant women with coronavirus disease 2019 (COVID-19). medRxiv 2020. [CrossRef]

58. Yang, H.; Sun, G.; Tang, F.; Peng, M.; Gao, Y.; Peng, J.; Xie, H.; Zhao, Y.; Jin, Z. Clinical features and outcomes of pregnant women suspected of coronavirus disease 2019. J. Infect. 2020, in press. [CrossRef]

59. Shanes, E.D.; Mithal, L.B.; Otero, S.; Azad, H.A.; Miller, E.S.; Goldstein, J.A. Placental Pathology in COVID-19. Am. J. Clin. Pathol. 2020, in press. [CrossRef]

60. Li, N.; Han, L.; Peng, M.; Lv, Y.; Ouyang, Y.; Liu, K.; Yue, L.; Li, Q.; Sun, G.; Chen, L.; et al. Maternal and neonatal outcomes of pregnant women with COVID-19 pneumonia: A case-control study. Clin. Infect. Dis. 2020, in press. [CrossRef] [PubMed]

61. Yin, M.; Zhang, L.; Deng, G.; Han, C.; Shen, M.; Sun, H.; Zeng, F.; Zhang, W.; Chen, L.; Luo, Q.; et al. Severe Acute Respiratory Syndrome Coronavirus 2 (SARS-CoV-2) Infection During Pregnancy In China: A Retrospective Cohort Study. medRxiv 2020.

62. Laake, I.; Tunheim, G.; Robertson, A.H.; Hungnes, O.; Waalen, K.; Håberg, S.E.; Mjaaland, S.; Trogstad, L. Risk of pregnancy complications and adverse birth outcomes after maternal A(H1N1) pdm 09 influenza: A Norwegian population-based cohort study. BMC Infect. Dis. 2018, 18, 525. [CrossRef]

63. Schwartz, D.A.; Graham, A.L. Potential Maternal and Infant Outcomes from (Wuhan) Coronavirus 2019-nCoV Infecting Pregnant Women: Lessons from SARS, MERS, and Other Human Coronavirus Infections. Viruses 2020, 12, 194. [CrossRef] [PubMed]

64. Gidlöf, S.; Savchenko, J.; Brune, T.; Josefsson, H. COVID-19 in pregnancy with comorbidities: More liberal testing strategy is needed. Acta Obstet. Gynecol. Scand. 2020, in press.

65. Centers for Disease Control and Prevention (CDC). Interim Considerations for Infection Prevention and Control of Coronavirus Disease 2019 (COVID-19) in Inpatient Obstetric Healthcare Settings. Available online: https://www.cdc.gov/coronavirus/2019-ncov/hcp/inpatient-obstetric-healthcare-guidance.html (accessed on 10 June 2020).

66. WHO. Coronavirus Disease 2019 (COVID-19). Situation Report_72. Available online: https://www.who.int/ docs/default-source/coronaviruse/situation-reports/20200401-sitrep-72-covid-19.pdf?sfvrsn=3dd8971b_2 (accessed on 10 June 2020).

67. Ai, T.; Yang, Z.; Hou, H.; Zhan, C.; Chen, C.; Lv, W.; Tao, Q.; Sun, Z.; Xia, L. Correlation of Chest CT and RT-PCR Testing in Coronavirus Disease 2019 (COVID-19) in China: A Report of 1014 Cases. Radiology 2020, in press. [CrossRef] [PubMed]

68. National Institutes of Health. Special Considerations in Pregnancy and Post-Delivery. 12 May 2020. Available online: https://www.covid19treatmentguidelines.nih.gov/overview/pregnancy-and-post-delivery/ (accessed on 10 June 2020).

69. Ashokka, B. Care of the Pregnant Woman with COVID-19 in Labor and Delivery: Anesthesia, Emergency cesarean delivery, Differential diagnosis in the acutely ill parturient, Care of the newborn, and Protection of the healthcare personnel. Am. J. Obst. Gynec. 2020, in press.

70. Groß, R.; Conzelmann, C.; Müller, J.A.; Stenger, S.; Steinhart, K.; Kirchhoff, F.; Münch, J. Detection of SARS-CoV-2 in human breastmilk. Lancet 2020. [CrossRef]

(C) 2020 by the authors. Licensee MDPI, Basel, Switzerland. This article is an open access article distributed under the terms and conditions of the Creative Commons Attribution (CC BY) license (http://creativecommons.org/licenses/by/4.0/). 